\title{
Habilidades de un buen docente en los diferentes modelos de escuelas. Tips para afrontar los retos del siglo XXI
}

Flores Hernandez, Aime Samara

Universidad de Pedagógica, México aime-01@hotmail.com

Balderas Baena, Sandy

Instituto de Huauchinango, México sandy.blbn@gmail.com
Ramírez Posadas, Maricruz

Universidad de Quintana Roo, México mramirez@uqroo.edu.mx
Resumen - El presente texto es un ensayo derivado de un trabajo más amplio denominado cualidades de un buen docente desde la perspectiva de los estudiantes de tres posgrados de la Universidad

Veracruzana, en el que se analizaron las principales Habilidades que se enaltecen en los profesores de acuerdo a diferentes modelos de escuelas, que a su vez responden a las condiciones y necesidades de la época y del contexto. En ese sentido, el objetivo del ensayo es reflexionar sobre cuáles son las habilidades que un docente debe tener de acuerdo a los modelos educativos más sobresalientes, al menos en México y, al mismo tiempo se ofrece un apartado en donde se aportan tips, en especial en tecnología, u orientaciones a los profesores para que puedan implementarlas en este exigente siglo XXI.

Palabras clave: Modelos educativos; Habilidades y cualidades docentes; TIC;

\begin{abstract}
This text is an essay derived from a broader work called qualities of a good teacher from the perspective of three postgraduate students of the Universidad Veracruzana, in which the main Skills that exalt in teachers according to different studies were analyzed. Models of schools, which in turn respond to the conditions and needs of the time and context. In that sense, the objective of the essay is to reflect on what are the skills that a teacher should have according to the most outstanding educational models, at least in Mexico and, at the same time, a section is provided where tips are provided, especially in technology, or guidance to teachers so they can implement them in this demanding 21st century.
\end{abstract}

Keywords: Educational models; teaching skills and qualities; TIC;
Interconectando Saberes, 2019

ISSN: 2448-8704
Fecha de Recepción: 10 de julio de 2019

Fecha de Aceptación: 14 de octubre de 2019

Fecha de Publicación: 31 de octubre de 2019 


\section{INTRODUCCIÓN}

El siglo $X X I$ supone muchas exigencias para los docentes, hoy más que nunca se habla de la necesidad de cambiar formas de enseñar y especialmente se escucha reiteradamente la urgencia de incorporar las nuevas tecnologías de la información y la comunicación en las aulas (TIC). En el presente trabajo sostenemos la tesis de que para transbordar los cambios a las aulas, antes los profesores deben reflexionar sobre sus cualidades y habilidades. Así, presentamos algunas de éstas que, en los diferentes modelos se han ponderado, ello para que los docentes miren en cuál de esos modelos se ubican. Finalmente damos algunas sugerencias de cómo se podría implementar algunas tecnologías a las aulas, ya que en el modelo educativo vigente, el uso de TIC es un imperativo.

\section{PARA EL MODELO DE ESCUELA NUEVA}

De acuerdo con Palacios (1981), la escuela nueva surgió en el siglo XIX como respuesta contestaría a los preceptos de la escuela tradicional, donde el maestro era el eje central del proceso educativo (ma- giostocentrismo) y los contenidos a aprenderse, la base de la enseñanza. Dado que no había tanta producción de libros, ni personas preparadas para enseñar; los conocimientos eran concebidos como saberes absolutos, inamovibles y asequibles para muy pocos; por eso los maestros celosamente medio los compartían con sus alumnos y solicitaban que se aprendieran literalmente sin cambio alguno, a base de memoria y repetición y quien no lo hacía podía ser castigado, golpeado o puesto en vergüenza por el maestro, de allí el valor del lema Jesuita, verdaderos maestros de la escuela tradicional: "las letras con sangre entran".

En ese sentido, un maestro de escuela nueva no es dueño del conocimiento, tampoco de la palabra ni de la dirección. Solo acompaña a los alumnos y se aprende bajos los preceptos de libertad, disfrute y creatividad.

Los pedagogos denominados de escuela nueva, por la innovación de sus ideas que a la fecha perduran -enlistarlos todos sería sumamente complicado, así como resaltar sus aportes- sostenían como tesis cen- 
tral al "paidocentrismo", es decir, que el centro del sistema escolar no era el maestro como se creía en la escuela tradicional, sino el niño, con su naturaleza peculiar. Comenio en la Didáctica Magna sostuvo con fehaciencia que el niño es el ser más importante sobre el que debe girar la enseñanza, los contenidos $y$ materiales escolares $y$, además, debe ser respetada su naturaleza. La naturaleza de un niño es aquello que le es propio, peculiar, natural, como la inquietud y la curiosidad. Con relación a esto, Rousseau decía en su libro Emilio o de la Educación:

Un niño es un ser sustancialmente distinto al adulto y sujeto a sus propias leyes y evolución, el niño no es un animal ni un hombre, es un niño (Rouseau, 1762, p.33).

Esa naturaleza hizo ver que era el maestro quien debía adaptarse al niño y no éste al maestro, en otras palabras, era más importante (y sigue siendo) el aprendizaje que la enseñanza. Luego entonces, el maestro para atender a los niños tiene que desarrollar ciertas cualidades que le permitan garantizar los aprendizajes.
Por supuesto, varios pedagogos des escuela nueva como Comenio, Freinet, Montessori, Dewey... analizan y proponen modelos de enseñanza dirigidos al logro de aprendizajes vivenciales, sin forzar la memoria, evitando la recepción pasiva de los niños. A partir de sus sugerencias, algunas de las habilidades de un maestro de escuela nueva son: parecer un miembro más del aula, sabe compartir la palabra y respeta la voz de los niños, recrear el aula para que los alumnos aprendan en movimiento, motiva y sabe cómo entusiasmar para aprender, favorece la curiosidad, el compañerismo, la libertad y la autonomía... Mucho se puede exponer de las propuestas pedagógicas de los precursores de escuela nueva.

Aunque la escuela nueva sólo va dirigida a niños, muchos preceptos pueden ser retomados para otros niveles educativos, pues la esencia es el alumno y el aprendizaje. Un aprendizaje autónomo y libre. 
Flores Hernandez, Aime Samara; Ramírez Posadas, Maricruz; Balderas Baena, Sandy

\section{MODELO DE TECNOLOGÍA}

EDUCATIVA

En México, en los 60s y 70s (Pansza et al, 2001) se incorpora en las escuelas un modelo educativo denominado Tecnología educativa, que para los 80 s se ve fuertemente cuestionado por un grupo de intelectuales considerados como críticos (principalmente los intelectuales de la UNAM: Díaz Barriga, Morán, Pansza, entre otros), quienes postulaban por una didáctica crítica, ya que desde su percepción la tecnología educativa no había logrado formar estudiantes reflexivos, y menos aún críticos.

La tecnología educativa busca cambiar esquemas tradicionales de enseñanza como el hecho de que el maestro sea siempre el protagonista del proceso de enseñanza y aprendizaje, que sea verbalista y controlador de la clase, además de que se conciba al alumno como ente pasivo y sólo receptor de mensajes.

Con la tecnología educativa, el maestro dejaba de ser la figura protagónica del proceso de enseñanza aprendizaje, pues se intensificaban el trabajo grupal y las dinámicas y técnicas de enseñanza. De esta manera, se evi- taba en todo momento que el maestro hablara más que los alumnos, para así favorecer la espontaneidad y autonomía de ellos (Hernández y Hernández, 2011).

Como se puede observar, en realidad el maestro nunca dejó de ser el centro del proceso de enseñanza-aprendizaje, su relación con los alumnos supuestamente ya no era vertical, pero esa imagen del maestro fue aparente, dado que el control siempre lo tenía él.

La tecnología educativa se sustenta de la teoría conductista, de la teoría de sistemas y del pensamiento tecnocrático. Vasconi (en Pansza, 1985) señala tres elementos característicos de este pensamiento: Ahistoricismo, Formalismo y Cientificismo

Esos elementos significan que la educación deja de ser considerada como una acción histórica y socialmente determinada; el pasado se queda en el pasado pues importa el aquí y el ahora: la educación se descontextualiza y se universaliza, es para todos. Los planes de estudio pueden ser trasplantados de un 
país a otro, sin mayor dificultad, ya que están lógicamente estructurados. Así, las consideraciones sociales e históricas son hechas a un lado y se da paso a una forma "científica" del trabajo educativo (Pansza1985).

Bajo esas consideraciones, el profesor en esta perspectiva, es conductista, se centra en las conductas de sus alumnos, modifica las que no son convenientes a través de una serie de programas. Deja de lado lo que no es observable o medible, lo que no es objetivo. Los problemas personales de cada alumno no son competencia del maestro en tecnología educativa.

Aquí las habilidades de un maestro se centran en saber planear $y$ diseñar la instrucción, evaluar objetivamente, aplicar técnicas de enseñanza e implementar materiales de enseñanza creativos.

\section{Modelo DE ESCUELA CRÍTICA}

En los 80 se intentó incorporar el modelo de escuela crítica en México, lo cual suponía un gran compromiso, pues un profesor: debía poseer vasto saber cultural, políti- co, estar enterado de la problemática actual y llevar esos problemas al aula para contrastarlo con el saber de los libros. Dichos libros y cualquier contenido no se aceptan como verdades absolutas, pues detrás de todo contenido subyace un discurso dominador intencional (véase Foucault, 1985).

De acuerdo con Bourdieu y Passeron (1977), la escuela reproduce ideología de la clase social dominante $\mathrm{y}$, los profesores consciente e inconscientemente son reproductores de esa ideología e incluso vioIentan simbólicamente a los alumnos a través de la transmisión de contenidos y a partir de la arbitrariedad pedagógica, tratan a los alumnos por igual, cuando ni un alumno es igual que otro. No aprende igual un alumno bien alimentado que aquel que le lloran las tripas por no desayunar, no es igual aquel que tiene en casa libros, canal de paga, posibilidades de conocer teatros, museos y de viajar, que aquel que en su vida ha salido de su ciudad o pueblo.

Bourdieu sostuvo que esas diferencias radican en los distintos capitales culturales; los alumnos 
Flores Hernandez, Aime Samara; Ramírez Posadas, Maricruz; Balderas Baena, Sandy

tienen capitales culturales distintos porque pertenecen a estratos sociales diferentes. Las ideas de Bourdieu corresponden a la teoría crítica y contribuyen a la didáctica crítica, justo porque el maestro tiene que considerar la realidad de cada estudiante y tratarlos de modo diferente. Eso no significa que "ayude" más a uno que otro, pero esas diferencias inciden directamente en el rendimiento y no deben ser ignoradas.

Las habilidades del maestro no deben limitarse a los planteamientos del conductismo, un profesor debe ser un crítico comprometido con sus alumnos y con la sociedad, busca la ecuanimidad y la equidad, instrumenta actividades que despierten el espíritu reflexivo y crítico, como los debates y las discusiones de los estudiantes dentro del aula.

Otros enfoques derivados de la situación actual. La didáctica medial y la perspectiva constructivista

En la escuela asisten alumnos que cada vez más se aburren en clases, faltan mucho, presentan actitudes de apatía y hasta desidia, por varias razones, pero una de ellas puede ser la influencia que tienen en sus vidas los medios de comunicación y entretenimiento (las nuevas tecnologías). El gran colorido de las pantallas no se compara con la clase opaca de un maestro que no usa las tecnologías en su clase y se conforma con el pizarrón $y$ el gis.

De acuerdo con la UNESCO los estudiantes están llamados a desempeñar un papel fundamental, ya que están en la vanguardia en la utilización de las nuevas tecnologias y las usan efectivamente en la vida diaria (UNESCO, 2005).

Fernando Gil (1998) comenta que la autoridad del maestro se ve minimizada por los medios tecnológicos. Esto es sencillo, el profesor deja de ser el único poseedor de conocimientos, la única vía de acceder a éstos. Pues ahora se puede aprender de las nuevas tecnologías, por ejemplo, aprender las lecciones en soportes grabados.

La realidad incita a que los profesores se actualicen y usen las tecnologías en sus escuelas, en lugar de competir con ellas. Así, en- 
tre las cualidades necesarias de un profesor es su actualización en el manejo de las nuevas tecnologías, y sobre todo su disposición para incorporarlas.

El contexto socio-histórico del país, la incidencia de la globalización, del neoliberalismo y la influencia de ideologías de mercado precisaron transformaciones a la escuela, como lo mencionara Hargreaves (1999), las reglas de la enseñanza y del trabajo de los docentes deben modificarse para estar acorde con los cambios sociales. Hoy se habla de una sociedad de la información y de la comunicación en la que las tecnologías no pueden ser ignoradas. De cierto modo, "este contexto nos obliga a regresar la mirada a la tecnología educativa y a la didáctica crítica, aunque con sentidos diferentes" (Hernández y Hernández, 2011,p 60). "Repensar una didáctica medial o didáctica de los medios, que no se constriña en fundamentar teórica y metodológicamente la trascendencia de los medios tecnológicos, sino que también nos muestre críticamente los efectos de su uso" (Hernández y Hernández, 2011, p 61). Esto es, un maestro debe sa- ber usar las tecnologías educativas, pero no solo instrumentalmente, sino saber las consecuencias de su uso y los contenidos que éstas transmiten, como las redes sociales y los innumerables mensajes que llegan a los estudiantes de edades diferentes.

Como se puede observar, las habilidades de un docente, son justamente que sea innovador, que implemente las nuevas tecnologías en el aula congruentemente con las competencias que quiere desarrollar en el alumnado, pero además sea crítico, sepa los efectos que éstas tienen en la vida de los estudiantes, sepa leer mensajes enajenantes $o$ subliminales de los medios y les enseñe a sus alumnos a interpretarlos y a no dejar que influyan en la forma de pensar y actuar.

La introducción de las TIC en educación no garantiza por si misma ni la inclusión ni la equidad social, como tampoco la mejora de la calidad o la innovación en la educación. Desafortunadamente, la visión que acompaña la introducción de las TIC presupone con frecuencia que el avance social y educativo se basa sólo en los progresos tec- 
Flores Hernandez, Aime Samara; Ramírez Posadas, Maricruz; Balderas Baena, Sandy

nológicos, dejando de lado el asunto de la exclusión social e inequidad que se propicia cuando dicha incorporación no toma en cuenta a sus actores (Díaz Barriga, et al en Díaz Barriga y Hernández, 2009, p. 67).

Hernández y Hernández (2011) proponen se preste atención en la didáctica medial. De esa manera, las habilidades que debe tener un maestro se amplían, pues no solo debe estar capacitado para usar las nuevas tecnologías, sino que enseña a los alumnos a ser críticos y reflexivos y a no aceptar ideologías impuestas por grupos hegemónicos, a no aceptar estereotipos.

Volviendo con lo que mencionábamos al inicio del este apartado, la misma situación social promueve cambios esquemáticos en el enseñar y en el aprender, donde el aprendizaje tiene mayor trascendencia que el enseñar, pues es el alumno el agente más importante en el proceso de enseñanza-aprendizaje.

Resulta que los alumnos son diferentes a los de antaño, ahora se aburren con mayor frecuencia y no aceptan tan fácilmente todo lo que los maestros dicen en el aula, pues algunos se atreven a refutar y a buscar información para desmitificar lo que los maestros dicen, y es que por años los conocimientos se han enseñado como verdades absolutas, cuando la verdad no existe.

Ante eso, las reformas educativas apuestan por estrategias de enseñanza que promuevan aprendizajes significativos, en síntesis, que se aprenda constructivamente. Sin embargo, esto poco se ha logrado porque sigue habiendo fallas en la formación docente, pues los profesores no logran cristalizar en el aula dicho constructivismo. Al respecto Carretero señala (1993, p.18):

Por tanto, en este punto nos encontramos con la siguiente paradoja: por un lado, el alumno posee mayor capacidad cognitiva que en edades anteriores, y ha adquirido también mayor cantidad de información sobre numerosas cuestiones. Sin embargo, en términos generales su rendimiento global y su interés por la escuela suele ser mucho menos que en los primeros cursos. En definitiva, es como si el sistema educativo estuviera desaprovechando la mejora que se ha producido en 
la mente de los alumnos y en vez de obtener un mejor partido, establecieran las condiciones para producir lo contrario.

De allí que las habilidades de un profesor sean esenciales en el constructivismo.

(...) básicamente puede decirse que es la idea que mantiene que el individuo -tanto en los aspectos cognitivos y sociales del comportamiento como en los afectivos- no es un mero producto del ambiente ni un simple resultado de sus disposiciones internas, sino una construcción propia que se va produciendo día a día como resultado de la interacción entre esos dos factores. En consecuencia, según la posición constructivista, el conocimiento no es una copia de la realidad (Carretero, 1993, p.21).

Luego entonces, un docente que enseña constructivamente debe poseer las siguientes habilidades:

- Concibe al conocimiento como algo que se construye junto con los otros. No como algo fijo y absoluto.

- Recupera saberes previos de los alumnos para enlazarlos con los contenidos a aprehenderse. Por eso se constituye en un puente entre lo que los estudiantes saben y lo que él va a enseñar como nuevo.

- Utiliza estrategias de enseñanza constructivista, es decir flexibles y adaptables.

Como puede observarse, son tantas las habilidades y capacidades que un maestro debe poseer, que nos lleva a pensar que no todo se puede lograr, porque un maestro es una persona con fortalezas y debilidades.

\section{TIPS PARA AFRONTAR LOS RETOS DEL SIGLO XXI}

La exigencia y reto para un docente, formado en un paradigma del siglo pasado, es el implementar las nuevas tecnologías en las aulas escolares, sobre todo por la dificultad que estriba su uso para una generación diferente.

Esta última década se ha caracterizado por la drástica forma en que las tecnologías de la información y de la comunicación han influido en la relación de estudiantes y maestros, al mismo tiempo que nuestro país evoluciona, los métodos de enseñanza también deben de avanzar. 
Flores Hernandez, Aime Samara; Ramírez Posadas, Maricruz; Balderas Baena, Sandy

Muchos de los profesores que se encuentran impartiendo cátedra en nivel superior aún se encuentran resistentes a darle paso al uso de las TIC en las actividades que desempeñan como docentes, sin darse cuenta de que estas nuevas tecnologías pueden ayudar a mejorar la experiencia enseñanza-aprendizaje dentro del salón de clases.

Por ello, a continuación proponemos algunas pistas para usarlas:

- Utilizar herramientas multimedia dentro de clases como presentaciones en diapositivas, video tutoriales, videos interactivos, imágenes que hagan conciencia, etc., ayudarán a crear un ambiente más dinámico y captar la atención de los alumnos.

Ejemplo de plataformas que brindan este tipo de herramientas:

- PowerPoint

- Emaze

- PowToon

- Prezi

En algún momento es necesario presentar a los alumnos mapas conceptuales, mentales, sinópticos, etc. Hacerlo muchas veces resulta una tarea difícil, pero ya existen he- rramientas digitales que permiten diseñar todos estos tipos de diagramas con el menor esfuerzo, algunos ejemplos de ello son:

- Popplet

- Lucid chart

Estas dos herramientas te ofrecen capturar y organizar ideas de forma rápida además de que cuentan con un diseño flexible.

En la actualidad internet está Ileno de una inmensa cantidad de información que puede ser consultada en cuestión de segundos, pero no todo lo que se encuentra en internet viene de fuentes confiables, es por ello que es necesario hacer consultas en sitios veraces, uno de ellos es: Google académico, que permite buscar información de diversas disciplinas en formatos como tesis, artículos e incluso libros $y$, además brinda la posibilidad de consultar las referencias y fuentes de cada texto.

- Redalyc. Este sitio web es parte de la Red de Revistas Científicas de América Latina y el Caribe, España y Portugal y funciona como un buscador de recursos académicos de carácter científico.

- Scielo. Esta hemeroteca da vi- 
sibilidad a distintos materiales académicos y literarios y cuenta con autores de todo el mundo.

La ausencia de los alumnos a las clases durante el periodo escolar, en la mayoría de las ocasiones representa un retraso en las actividades programadas de la materia, para darle solución a esto existe una variedad de plataformas y herramientas digitales que permitan comunicar, intercambiar archivos y revisar actividades desde cualquier distancia a los docentes con los alumnos, solo se necesita conexión a internet y ¡Listo! Ejemplo de estas plataformas son:

- Moodle: El maestro puede subir actividades en formato video, imágenes, etc., es la plataforma de código abierto más conocida y usada.

- Chamilo: El maestro puedes subir y acceder a cursos gratuitos, además puedes subir y descargar toda clase de archivos.

Esas son algunas sugerencias que puede tomar en cuenta un docente para integrar el manejo de las TIC y hacer sus clases más didácticas.

\section{CONCLUSIÓN}

Las cualidades entendidas como atributos o características buenas de los docentes, como se observó, son distintas en los diferentes modelos de escuelas, en tanto que se ponderan ciertos aspectos del maestro porque responden a un modelo de escuela, sociedad e incluso de política educativa; esto significa que las habilidades de un buen docente se perfilan y se condicionan para responder a intereses particulares. Los tiempos han cambiado, por tanto la enseñanza debe cambiar, como dijera Hargreaves(1999), pero dichos cambios deben ser reflexionados $y$ meticulosamente analizados, de allí que este ensayo permitió al menos acercarse al conocimiento de cómo ha variado la enseñanza y las habilidades de los docentes $y$, por supuesto, esperamos que despierte el deseo de los profesores de modificar elementos de sus esquemas de enseñanza enraizados en un modelo de escuela tradicional o quizás conductista, empezar por analizar sus actitudes y tratar de implementar las TIC, es ya es un avance. 


\section{BIBLIOGRAFÍA}

Bourdieu, P. y Passeron, (1977). La reproducción. Barcelona: Caída.

Carretero M., (1993). Constructivismo y educación. Argentina: Luis Vives.

Díaz Barriga y Hernández, (2009). Aprender y enseñar con TIC en educación superior: contribuciones del socioconstructivismo. México: UNAM.

Durkheim, (1985). Educación como socialización. Salamanca: Sígueme.

Foucault, Michel, (1985). Vigilar y castigar. México: Siglo XXI.

Hargreaves, (1999). Profesorado, cultura y postmodernidad.

Hernández, M. G, (2012). Práctica docente. Más allá de cuatro paredes, pizarrón y mesabancos.

Hernández, M. G. y Hernández, (2011). El impacto de las TIC en la educación. Por una didáctica medial. En Rodríguez (coord.) Políticas de educación superior. México: Libris.

Pansza, M.; Pérez, E.; Morán, P., (1987). Operatividad de la didáctica. México. Guernika.

Rousseau, J., (2000). Emilio o de la Educación. Consultado en http//www.ar/educar/site/educar/kbee :/educar/portal-content/taxonomíarecuersos/Emilio.pdf

UNESCO. (2005). Hacia las sociedades del conocimiento. Informe Mundial de la Educación. París: UNESCO. 